\title{
Ignorance, Presuppositions, and the Simple View
}

\author{
Michael BLOME-TILLMANN \\ University of Cambridge \& McGill University \\ mb938@cam.ac.uk
}

\begin{abstract}
Jonathan Jenkins Ichikawa has presented a series of examples that are meant to spell trouble for Presuppositional Epistemic Contextualism (PEC). In this short article I shall aim to establish two things. First, I shall argue that even if Ichikawa's examples were viable counterexamples to PEC, they would not threaten the key ideas underlying the account in Knowledge and Presuppositions. The philosophically interesting work that is done in that article remains unaffected by Ichikawa's alleged counterexamples. In the second part of the paper, I shall argue that the examples are not in fact successful counterexamples to PEC. The data emerging from Ichikawa's examples can be accounted for within the framework of PEC.
\end{abstract}

\section{The Simple View}

To begin with, let me repeat briefly how Presuppositional Epistemic Contextualism (PEC) is formulated in Blome-Tillmann 2009. Here is the core principle underlying PEC, which is obviously inspired by Lewis 1996:

(L) $\quad x$ satisfies 'knows $p$ ' in context $C \leftrightarrow x$ 's evidence eliminates every $\neg p$ world, except for those that are properly ignored in $C$.

Once (L) is in place, PEC offers an explication of what it means for a $\neg p$-world to be properly ignored in a context $C$ that differs from Lewis's in employing the notion of a pragmatic presupposition. Now, it is important to note that (L) is a bi-conditional. The examples offered by Ichikawa are intended as counterexamples to the right-to-left direction of $(\mathrm{L})$; that is, they are meant to be examples in which we intuitively do not satisfy 'knows $p$ ' even though all $\neg p$-worlds that PEC singles out as not properly ignored are eliminated. In other words, if Ichikawa's examples are correct, they are cases in which PEC predicts that there is 'knowledge' when, intuitively, there isn't.

Let us assume, for the moment, that Ichikawa's examples succeed in putting pressure on the right-to-left direction of (L) when combined with PEC's account of proper ignoring, or-as I shall call it-epistemic relevance. Couldn't the defender of PEC simply give up the biconditional (L) while retaining the guiding idea underlying PEC - namely, the idea that 'knowledge'-ascriptions are sensitive to what is pragmatically presupposed at the context of ascription? The most straightforward way to implement such a strategy is by replacing the bi-conditional (L) with the less committal conditional (L'):

(L') $\quad x$ satisfies 'knows $p$ ' in context $C \rightarrow x$ 's evidence eliminates every $\neg p$ world, except for those that are properly ignored in $C$.

While such a retreat from (L) to ( $\left.\mathrm{L}^{\prime}\right)$ may seem to weaken PEC considerably, nothing much is, in fact, lost by such a move. To see this consider the following principle, which I have elsewhere called the Simple View: 
The Simple View (SV):

$x$ satisfies 'knows $p$ ' in context $C \rightarrow x$ 's evidence eliminates all $\neg p$-worlds that are compatible with what is pragmatically presupposed in $C$. ${ }^{1}$

The Simple View is entailed by both (L) and ( $\left.\mathrm{L}^{\prime}\right)$, in conjunction with my rules of proper ignoring (in particular, my Rule of Presupposition). So while (SV) is logically weaker than PEC as defined in my (2009), it nevertheless makes an interesting and important philosophical claim about the role of pragmatic presuppositions in the semantics of 'knowledge'-attributions. According to the Simple View, the semantic content of 'knows $p$ ' is sensitive to what is pragmatically presupposed at the context of ascription. In other words, a world that is compatible with what is pragmatically presupposed in a context $C$ must be eliminated by one's evidence for one to satisfy 'knows $p$ ' in $C$. The Simple View thus captures nicely one of the core insights behind the approach defended in Knowledge and Presuppositions.

Moreover, since the Simple View merely explicates a necessary condition for the satisfaction of 'knows $p$ ' in a context $C$ but not a sufficient one, we can sidestep Ichikawa's objections to PEC by retreating from (L) to (SV). And, of course, the Simple View is still philosophically interesting and fruitful. Despite the fact that it does not offer an analysis or definition of the satisfaction of 'knows $p$ ' at a contextsomething that, arguably, cannot be done anyhow - the Simple View still provides us with a clear and precise contextualist explanation of the data that are typically used to motivate epistemic contextualism - data such as those emerging from DeRose's (1995) Bank Case or Cohen's (1999) Airport Case. What is more, the Simple View also affords us with an explanation or resolution of sceptical puzzles along the lines provided in my 2009, and also explains a number of other phenomena addressed there. In summary, even if we abandon (L), we can stay true to the spirit of PEC by endorsing the Simple View. If the Simple View is right, and Ichikawa's examples do not (and are not meant to) call that view into question, then pragmatic presuppositions still play centre stage in the semantics of 'knowledge'-attributions.

\section{The Examples}

Despite the availability of the above concessive response, Ichikawa's examples are extremely interesting and it is illuminating to consider them in more detail. Ichikawa presents a series of different examples, building up to the case that he eventually takes to put pressure on PEC. Instead of skipping over the interim examples, it is instructive to take a closer look at each of them in turn, as most of the cases can be responded to along similar lines. Here is Ichikawa's first example:

Example 1: (at a party)

Emily: The woman in the corner wants to speak to Sunil.

Shari: Yes, she does. But Sunil hasn't looked at her in minutes, and she didn't seem to notice him then. He has no reason even to think she's still there.

As Ichikawa points out, if Shari were to assert 'Sunil knows that there is a woman in the corner', she would, intuitively, be speaking falsely. But note that it is pragmatically presupposed at the context that there is a woman in the corner: both, Emily and

\footnotetext{
${ }^{1}$ See Blome-Tillmann forthcoming, Ch. 1.
} 
Shari know that there is a woman in the corner, and they behave, in their use of language, as if it is common ground that there is a woman in the corner.

Now, Ichikawa claims that this is a counterexample to PEC since PEC's Rule of Presupposition does not single out as epistemically relevant (or not properly ignored) any worlds in which the woman under consideration has left the corner. However, PEC can easily accommodate the case. To see this consider the following two rules of proper ignoring:

\section{Rule of Actuality (RA):}

The subject $x$ 's actuality is never properly ignored.

\section{Rule of Resemblance (RR):}

If a world $w$ is not properly ignored in a context $C$ in virtue of rules other than this, then all worlds $w$ ' that are close to $w$ are not properly ignored in $C$ either. ${ }^{2}$

The conjunction of these two rules entails that all $\neg p$-worlds that are close to the subject's actuality must be eliminated by the subject's evidence for her to satisfy 'knows $p$ '-in any context whatsoever. The two rules' combined effect is therefore somewhat similar to that of a safety condition on 'knowledge'. While the conjunction of (RA) and (RR) entails that one does not 'know $p$ ' if there are uneliminated nearby $\neg p$ worlds, the safety condition on knowledge entails that one does not know $p$ if there are nearby $\neg p$-worlds in which one believes $p .{ }^{3}$ What is important for the present discussion, however, is that the above rules allow us to account for Example 1. Sunil does not 'know' that there is a woman in the corner because his evidence fails to eliminate precisely those nearby worlds in which the woman has left the corner to fetch a drink from the bar (or to make a phone call, go to the bathroom, etc.). Thus, PEC can very well explain why an utterance of 'Sunil doesn't know that there's a woman in the corner' seems true in the context of Example $1 .{ }^{4}$

Ichikawa presents further similar examples that are meant to be counterexamples to PEC. Consider the following case:

\footnotetext{
${ }^{2}$ Cp. Lewis 1996, p. 556. Note that Lewis does not define his rule of resemblance in terms of closeness or overall similarity between worlds, but rather in terms of 'salient resemblance'. I discuss Lewis's version of the rule in detail in Chapter 5 of (Blome-Tillmann forthcoming).

${ }^{3}$ See Williamson 2000, p. 147 for a discussion of safety.

${ }^{4}$ Ichikawa briefly addresses but then dismisses the idea of using the Rule of Resemblance to respond to his examples: 'The Rule of Resemblance is much vaguer, so it is difficult to apply it with as high confidence, but there is no obvious reason to think that it applies to $w$; there is no straightforward sense in which $w$ saliently resembles actuality [...] in a way that should mandate its inclusion on resemblance grounds. We may stipulate, for instance, that it's not the case that the woman in question actually very nearly decided to leave the corner at the time she leaves in $w$.' I am not sure why Ichikawa thinks that 'there is no straightforward sense in which [the relevant counterpossibility] saliently resembles actuality', given that Shari has just brought up the possibility as a relevant alternative and given that both Emily and Shari clearly consider it a possibility that easily could have occurred. Moreover, note that my formulation of (RR) in the main text does not rely on Lewis's notion of salient resemblance but rather on an intuitive and undefined notion of closeness or resemblance. We can, as I have argued elsewhere (Blome-Tillmann forthcoming), call this type of closeness epistemic closeness. On this approach, worlds in which the woman has left the corner are epistemically close to Sunil's actuality and must therefore be eliminated by Sunil's evidence in all conversational contexts whatsoever, independently of what Emily and Shari attend to or pragmatically presuppose (see Blome-Tillmann forthcoming for further discussion of epistemic closeness).
} 


\section{Example 2:}

Emily: It was Laura who ate the last cookie.

Shari: Yes. But Ravi doesn't know that. He doesn't even know that the cookies have all been eaten.

Analogously to Example 1, we may assume that there are nearby worlds in which the proposition that Laura ate the last cookie is false. For instance, we may assume that there are nearby worlds in which Emily ate it or in which the last cookie was removed from the jar but not eaten, etc. Since Ravi's evidence fails to eliminate these nearby counter-possibilities, Ravi fails to satisfy 'knows that Laura ate the last cookie'. Again, the combination of (RA) and (RR) provides us with a straightforward explanation of the data emerging from Ichikawa's examples. ${ }^{5}$

To be fair, Ichikawa himself is not content with the above examples. As he points out, the defender of PEC has another response available to her, in addition to the one I just outlined. As Ichikawa admits - and as I point out in my (2009, pp. 259-60) only beliefs that are properly based can constitute knowledge. Since the subjects in the above examples do not seem to have properly based beliefs, or so Ichikawa argues, PEC can easily account for the datum that the subjects in those cases do not have 'knowledge'. For this reason, Ichikawa amends his examples. Consider now the following:

\section{Example 3:}

Emily: It was Laura who ate the last cookie.

Shari: Yes. But Ravi doesn't know that. He doesn't even know that the cookies have all been eaten.

Emily: Doesn't he? He sees the empty cookie jar, and he's asking who ate the last cookie.

Shari: But he didn't see it get eaten. For all Ravi knows, Laura might have taken the last cookie and saved it for later.

Emily: Good point. Do you think he'll be upset when he learns that it was eaten, and that it was Laura who ate it?

Ichikawa again has it that Ravi does not satisfy 'knows that Laura ate the last cookie', even though Ravi now has, we may assume, a properly based belief and it is pragmatically presupposed that Laura ate the last cookie. How can PEC account for this datum?

There are at least two plausible responses on behalf of PEC. First, the defender of PEC can respond along the lines already outlined above, by pointing out that Ravi fails to 'know' that Laura ate the last cookie because his evidence fails to eliminate

\footnotetext{
${ }^{5}$ In addition to claiming that the above examples are counterexamples to PEC, Ichikawa argues further that 'according to PEC, standard uses of ' $x$ doesn't know $p$ ' will never turn out true', because 'knows that $p$ ' is a factive verb and as such carries the presupposition that $p$ : thus, speakers uttering a sentence of the form ' $x$ doesn't know $p$ ' pragmatically presuppose $p$. Now, it is not clear why Ichikawa thinks that it follows that an assertion of that form would usually not be true. For remember that, according to PEC, rules other than the Rule of Presupposition can make a counter-possibility relevant. Indeed, the remaining Lewisian rules of proper ignoring can make $\neg p$-worlds relevant, too. Consider, for illustration, the most extreme case in which ' $x$ doesn't know $p$ ' is uttered in a scenario in which $x$ is located in a $\neg p$-world. It follows right away, from the Rule of Actuality, that ' $x$ does not know $p$ ' is true in any context whatsoever and thus that there are numerous truthful standard uses of ' $x$ doesn't know $p$ '.
} 
certain nearby counter-possibilities or worlds in which Laura did not eat the last cookie. This response is plausible, since there are undoubtedly nearby worlds in which, for instance, Laura took the last cookie but saved it for later, or took it and disposed of it because it had gone stale, etc. Now, it might seem implausible to some that, as is the case on this view, Ravi does not satisfy 'knows that Laura ate the last cookie'. But it is worthwhile noting that, even though Ravi does not satisfy 'knows that Laura ate the last cookie', he nevertheless satisfies 'knows that it is extremely likely that Laura ate the last cookie'. ${ }^{6}$

The second response available to the defender of PEC relies on what I have elsewhere (2012) called the Rule of Evidence-Based Ignoring:

\section{Rule of Evidence-Based Ignoring (REBI):}

If the speakers in $C$ ignore $w$ because $w$ is eliminated by their evidence, then $w$ is not properly ignored in $C^{7}$

It is eminently plausible that, in Example 3, Shari and Emily pragmatically presuppose that Laura ate the last cookie because they know that Laura ate the last cookie (for simplicity's sake, let us assume that they saw Laura eat it). Then, according to (REBI), worlds in which Laura did not eat the last cookie are not properly ignored in the context of Example 3, and we have a straightforward explanation for why Ravi does not satisfy 'knows that Laura ate the last cookie'.

Effectively conceding this point, Ichikawa presents a final example in the concluding section of his paper:

\section{Example 5:}

Emily: Look, the cookie jar is empty!

Shari: I wonder who ate the last cookie. I bet it was Laura who ate it.

Emily: You are probably right. Laura does love cookies. Still, we can't be sure. It could have been someone else.

Shari: I guess. But I'm guessing it was Laura.

Emily: I'm not saying you're wrong, I'm just reminding you that we didn't see it happen. In fact, come to think of it, we don't know for sure that anybody ate it. Maybe Laura took it and saved it for later.

Shari: While I admit that that is a possibility, I consider it very unlikely. I'm going to go ahead and just assume that it was eaten.

Emily: Yeah, that's probably a pretty good working assumption.

Shari: Do you think Ravi knows it was Laura who ate the last cookie?

Emily: Does he know? No-Ravi doesn't even know that the cookie

\footnotetext{
${ }^{6}$ Ichikawa (Section 6) furthermore proposes an argument from 'minimal pairs', which is meant to spell trouble for my reliance on the Rule of Resemblance. However, I do not share Ichikawa's intuition that 'Ravi knows that somebody ate the last cookie' is true in his example, since, similarly to Example 3 in the main text, Ravi's evidence fails, in Ichikawa's example Cleft III, to eliminate the nearby possibility that the last cookie was taken but not eaten.

${ }^{7}$ A counterfactual cousin of (REBI) is the following principle: If the speakers in $C$ ignore $w$, but would not do so if $w$ were compatible with their evidence, then $w$ is not properly ignored in $C$. Note also that (REBI) might have to be refined to talk about the speakers' beliefs that their evidence eliminates $w$ rather than the fact that it does.
} 
was eaten. But he probably suspects that it was eaten, and that Laura is the one who ate it. And he's probably right.

Again, Ichikawa has it that it is pragmatically presupposed that Laura ate the last cookie in this example and that PEC therefore has no means of explaining why worlds in which Laura did not eat the last cookie are epistemically relevant. However, Ichikawa's assumption that, in the context of the example, it is pragmatically presupposed that the cookie was eaten is dubious. ${ }^{8}$ Even though Emily and Shari agree to use the proposition that Laura ate the last cookie as a working assumption, it does not automatically follow that it is pragmatically presupposed at their context. In fact, as I have argued in the paper, pragmatic presuppositions and assumptions are rather different kinds of propositional attitudes:

\begin{abstract}
[I]t is important to note that one can assume a proposition $p$, for the purposes of one's conversation, while at the same time failing to pragmatically presuppose $p$-in fact, while at the same time pragmatically presupposing $\neg p$. To illustrate this possibility consider a case in which the leader of a discussion asserts 'We all know it's false, but let's assume that pigs can fly.' Interestingly, for the audience to fully accommodate this utterance they do not only have to comply with the speaker's request and assume that pigs can fly, they rather also have to accommodate the speaker's claim to the effect that pigs cannot fly, that is they have to pragmatically presuppose that proposition. [...] Thus, once the mentioned utterance is fully accommodated into the context, the speakers will still be disposed to behave, in their use of language, as if they believed it to be common ground that pigs cannot fly, even though they now assume that they can. (BlomeTillmann 2009, Sect. 10, pp. 279ff.).
\end{abstract}

Given these considerations it can be seen that Example 5 is a case of assumption without pragmatic presupposition. Indeed, Shari's and Emily's very utterances in Example 5 are strong indicators that it is not pragmatically presupposed, in the context of Example 5, that Laura ate the last cookie. For if both were behaving, in their use of language, as if it was common ground that Laura ate the last cookie, then they surely would not assert sentences such as 'I wonder who ate the last cookie', 'I'm guessing it was Laura', and 'Maybe Laura took it and saved it for later'. Moreover, note that if it was pragmatically presupposed that Laura ate the last cookie, an adequate response to an utterance of 'Laura ate the last cookie' should be 'Yes, sure. But why are you stating the obvious?' But such an utterance would, no doubt, be out of place in the context of Example 5. ${ }^{9}$

One might think that while it is not pragmatically presupposed that Laura ate the last cookie towards the beginning of Example 5, pragmatic presuppositions shift after Emily proposes to use the proposition at issue as a working assumption. But again, that view is implausible, for Emily and Shari are still disposed to assert a variety of propositions that they should not be disposed to assert if they were disposed to treat the proposition that Laura ate the last cookie as part of the common ground. For instance, Emily and Shari are still disposed to assert 'Laura might not have eaten the last cookie', or to respond 'Someone else might have eaten the last cookie', if asked whether Laura ate the last cookie. Similarly, they are still disposed to assent, if asked whether someone else might have eaten the last cookie and to dissent and object to

\footnotetext{
${ }^{8}$ Ichikawa 2014, p. xxx: 'I take it that in this context, 'Ravi knows that the cookie was eaten' is false, even though it is [pragmatically] presupposed that the cookie was eaten [...].'

${ }^{9}$ I also take it that Shari's last utterance in Example 5 is infelicitous: Shari should have uttered 'Do you think Ravi knows whether Laura ate the last cookie?' instead of 'Do you think Ravi knows it was Laura who ate the last cookie?'
} 
utterances of sentences that presuppose that Laura ate the last cookies. For instance, Emily and Shari would surely object, if a third person joined the conversation and asserted 'Since Laura ate the last cookie, she can't have saved it for later!' Utterances of this kind are infelicitous in the context of Example 5 precisely because it is not pragmatically presupposed that Laura ate the last cookie.

To sum up, it is assumed in the context of Example 5 that Laura ate the last cookie. But it is not pragmatically presupposed. PEC, therefore, has again a straightforward explanation for why Ravi does not satisfy 'knows that Laura ate the last cookie'. ${ }^{10}$

\section{Conclusion}

I have argued that the data and alleged counterexamples that Ichikawa marshals against Presuppositional Epistemic Contextualism (PEC) do not pose a threat to the view. Moreover, I have argued that even if they were effective counterexamples to the view presented in my (2009), they would still not succeed in calling into question the guiding idea underlying Presuppositional Epistemic Contextualism-namely, that 'knowledge' attributions are sensitive to what is pragmatically presupposed in the context of ascription.

\section{References}

Blome-Tillmann, Michael 2009: 'Knowledge and Presuppositions'. Mind, 118(470), pp. 241-94.

Blome-Tillmann, Michael 2012: 'Presuppositional Epistemic Contextualism and the Problem of Known Presuppositions'. In Brown and Gerken 2012, pp. 104-19.

Blome-Tillmann, Michael 2014: Knowledge and Presuppositions. Oxford, OUP.

Brown, Jessica and Gerken, Mikkel (eds) 2012: Knowledge Ascriptions. Oxford: OUP.

Cohen, Stewart 1999: 'Contextualism, Skepticism, and the Structure of Reasons'. Philosophical Perspectives, 13, pp. 57-89.

DeRose, Keith 1995: 'Solving the Skeptical Problem'. The Philosophical Review, 104, pp. 1-52.

Lewis, David 1996: 'Elusive Knowledge'. Australasian Journal of Philosophy, 74, pp. 549-567.

Williamson, Timothy 2000: Knowledge and Its Limits. Oxford, OUP.

\footnotetext{
${ }^{10}$ Note finally that my initial response to the previous examples-relying on the conjunction of (RA) and (RR) - will also deliver promising results here. Given that there are nearby worlds in which the cookie was not eaten, but thrown out or kept for later, Ravi fails to 'know' that Laura ate the cookie, as his evidence fails to eliminate those nearby worlds in which the cookie was not eaten.
} 